\section{As revistas mudam porque os suportes mudam: panorama do produto em formatos digitais}

The magazines change because the media change: an overview of the product in digital formats

\author{
Tatiana Maria Silva Galvão Dourado
}

\section{Resumo}

Propõe-se associar o panorama histórico da digitalização das revistas jornalísticas com a delimitação teórica acerca das materialidades no campo das Ciências da Comunicação. Para isso, é apresentado o processo de transição e consolidação do produto específico nos formatos digitais, desde os "teletexts magazines", nos anos 1980, até as atuais "revistas sociais", que, novamente, reorienta a lógica de distribuição e consumo de notícias. A pesquisa é possibilitada pelo método de revisão de literatura com foco na linha evolutiva das revistas, ainda escassa, e nos estudos sobre materialidades, exemplificada com estudos de casos ilustrativos, com intuito de
Mestranda do Programa

de Comunicação e Culturas

Contemporâneas na Universidade Federal da Bahia (UFBA), especialista em Jornalismo e Convergência Midiática, Salvador, BA- Brasil, e-mail: tatianamaria.dourado@gmail.com

Palavras-chave: Jornalismo online. Revistas digitais.

Materialidades da Comunicação. 
compreender as diferentes atuações do produto nas interfaces virtuais.

\begin{abstract}
This paper proposes to link the historical overview of the digitization of news magazines with the theoretical definition of materiality on the field of Communication Sciences. For this, we present the process of transition and consolidation of specific product in digital formats, from "teletexts magazines" in the 1980s, to the current "social magazine", which again redirects the logic of distribution and consumption of news. The survey is constructed using the method of literature review focusing on the evolutionary line of magazines, still scarce, and studies on materiality, exemplified with illustrative case studies, in order to understand the different performances of the product in the virtual interfaces.
\end{abstract} Keywords: Online journalism. Digital magazines. Communication materiality.

\title{
Introdução
}

As revistas não eram tão diversas quando só existam no suporte impresso. Agora, mudam de periodicidade ou de tamanho (magazine $20 \times 26,5 \mathrm{~cm}$; americano $-17 \times 26 \mathrm{~cm}$; francês $-12 \times 19 \mathrm{~cm}$; Piauí $-26,5 \times$ $34,8 \mathrm{~cm}$ ), mas mantêm os seus principais aspectos: o folheio, a portabilidade, a estrutura (capa e miolo), as linguagens (textos, fotografias/ ilustrações e infográficos), a profundidade/análise dos fatos e a liberdade em pautar assuntos não factuais (hard news). O conceito do produto tem sido, há tempos, reformatado em programas audiovisuais, como os televisivos ${ }^{1}$, mas, ao que parece, a identificação imediata da sociedade em relação ao produto remete sobremaneira às publicações desenvolvidas para o suporte impresso.

Partindo do pressuposto de que os meios de comunicação são capazes de conviver de forma complementar - portanto, negando qualquer tipo de "substituição" ao impresso -, este artigo contempla as práticas midiáticas distribuídas exclusivamente em formatos digitais. O objetivo é, em uma

1 O Fantástico, da Rede Globo, e o Domingo Espetacular, da Record, podem exemplificar a afirmação. 
primeira etapa, reconstruir as fases pelas quais transitaram as revistas jornalísticas no percurso da digitalização, com intuito de apresentar, também, a evolução dos dispositivos eletrônicos de consumo de informação. Em segui$\mathrm{da}$, os suportes utilizados em tais fases serão compreendidos à luz das teorias das materialidades, fundamentação priorizada especialmente devido à pluralização dos formatos de revistas na plataforma digital. Exemplos de publicações são inseridos no sentido de ilustrar a argumentação da pesquisa.

\section{0 percurso de digitalização das revistas: da mídia eletrônica à binária}

A Acorn User Magazine, lançada em 1982, é uma das primeiras publicações denominadas "revista" a utilizar a tecnologia eletrônica para comunicar, no caso, informações sobre os computadores da marca britânica "Acorn"2 para o seu público interessado. Nesse primeiro ano, iniciou-se a veiculação das informações por correio eletrônico (e-mail) ou comunicado do conteúdo impresso para assinantes. As cinco edições publicadas no ano de lançamento, assim como todas as outras, até o ano de 2003, estão atualmente disponíveis online $e^{3}$ na íntegra.

A cronologia da mídia digital para revistas desenvolvida por Tony Quinn, autor do site Magforum.com, é geralmente usada nos poucos estudos acadêmicos que se dedicam ao assunto. Em seu trabalho, ressalta a mudança na cultura interna da redação da revista Acorn User, que no mesmo ano abdicou das máquinas de escrever e inseriu na redação o microcomputador Acorn BBC Micro, que possibilitava o armazenamento do conteúdo em rede, manuseado com disquete ou em um disco rígido de $5 \mathrm{MB}$, conseguindo enviar as informações para uma impressora matriz (QUINN, 2007).

Essa revista, especializada em informática, protagonizou as mudanças no sistema de computação da imprensa, enquanto experimentava o lançamento dos microcomputadores fabricados pela empresa Acorn User. Nesse sentido, inseriu como data marcante seguinte o dia 26 de abril de 1985: "Steve Furber e Sophie Wilson, da Acorn Computer, entregaram o primeiro chip do ARM (Acorn Risc Machine). ARM se tornou o primeiro chip do Risc (Reduced Instruction Set Computer) para alimentar um computador predominante" (QUINN, 2007).

2 A empresa foi fundada no mês de dezembro do ano de 1978 e lançou computadores como os Acorn Electron, o BBC Micro e o Acorn Archimedes, aparelhos consumidos entre os anos 1980-1990 e que serviram de base para o desenvolvimento de hardwares.

3 Disponível em: <http://migre.me/9Zp5G.>. Acesso em: 21 jul. 2012. 
Um ano depois, em 1983, a revista norte-americana Time estampou em sua capa a imagem do computador pessoal, acompanhado da frase: "The computer moves in", simbolizando as novas potencialidades que a sociedade adquire com a tecnologia: "A personal computer, it says, can send letters at the speed of light, diagnose a sick poodle, custom-tailor an insurance program in minutes, test recipes for beer", diz trecho da edição", apontando caminhos aos leitores. Em vez do tradicional "homem do ano", naquela capa a homenagem foi dedicada à "máquina do ano".

Jornais e revistas acompanharam o desenvolvimento do suporte eletrônico, na transição dos anos 1980-1990, a partir de tentativas como: teletexto - serviço eletrônico que fornece informações textuais na tela e é usado por emissoras de televisão ou entidades privadas; audiotexto - serviço informativo oferecido em mensagem gravada em áudio, hoje é usado de modo preponderante em call centers; jornal por fax - difundido por meio de aparelho de fax durante a madrugada para assinantes (ZAMITH, 1999); ou publicações distribuídas em CD-ROM. Conforme a trajetória traçada por José Pedro Souza, "[...] essas primeiras experiências falharam, segundo os estudos que foram feitos, devido à falta de motivação da audiência por uma tecnologia pouco atraente, cara e pouco amiga do utilizador. A Internet, porém, mudou as coisas" (SOUZA, 2003).

Os CD-ROM (Compact Disc Read-Only Memory), criado em 1985, permitiram, em um primeiro momento, que as revistas pudessem armazenar e distribuir conteúdo - que não poderia ser alterado, somente lido - por meio do dispositivo. O jornalismo começou a se apropriar do CD-ROM no fim dos anos 1980, primeiramente com edições criadas por empresas de software como a Microsoft: "[...] desde entonces la edición electrónica, como reunión de contenidos de procedencia diversa, encuentra en la Red su máxima expresión: la edición como sistema, que no como resultado o como producto" (LEIVA, 2007, p. 21).

As publicações encontravam nos suportes eletrônicos oportunidades para dinamizar a distribuição do conteúdo, sem abdicar da vertente impressa, com a qual trabalha a grande maioria dos principais títulos. No contexto das revistas culturais da Espanha, a pesquisadora Maria Trinidad García Leiva (2007) acredita que o impacto da tecnologia eletrônica afetou o processo produtivo das revistas segmentadas a partir dos seguintes aspectos: inserção de novos profissionais na redação (repórter/editor online), redução do tempo na veiculação da notícia e na cadeia de produção (já que não há a etapa de impressão, primeiro, com o CD-ROM, depois,

4 Disponível em: <http://migre.me/9ZAzx.>. Acesso em: 22 jul. 2012. 
com a internet), alteração nas formas tradicionais de distribuição e comercialização; novas possibilidades de acesso ao conteúdo (e-mail, assinaturas) e publicidade; além da leitura (LEIVA, 2007, p. 22).

No Reino Unido, a primeira revista interativa em CD-ROM, a Unzip, foi lançada no ano de 1995, pela editora especializada em publicação digital, a IPC Media, ao custo de $£ 15.99$ e com tiragem de 20 mil. "Ao CD-ROM faltava profundidade (e custo mais baixo) de uma revista impressa, além da qualidade visual da TV ou a emoção de um jogo de computador", opina Quinn (2007, tradução nossa). O período também foi marcado pela publicação dos covermounts, produtos complementares ("extras") que vinham armazenados em softwares, dentro dos CD-ROM, anexados às capas das revistas.

Quinn (2007) aponta a estreia, ainda no ano de 1995, de websites de revistas no contexto britânico, apontando as especializadas Uploaded.com (da Loaded) e o nme.com (da New Musical Express). Depois de aproximadamente dez anos, em 2006, surgiram as revistas interativas em formato website, possibilitadas pela editora Dennis, com a masculina MonkeyMag.co.uk (CUNHA, 2011, p. 29). É escassa a bibliografia acadêmica que se dedica à história de digitalização das revistas jornalísticas, estando ausente a determinação, por exemplo, do primeiro título mundial a lançar um website.

Segundo Cunha (2011), no Brasil, a revista Manchete foi a primeira a criar uma página na web, no dia 11 de novembro de 1995. A experiência foi feita disponibilizando o conteúdo da edição 2275. "O site foi resultado de parceria do empresário Adolpho Bloch, dono da revista, com o Banco Rural, que disponibilizou espaço na página http://br.homeshopping. com.br/bloch" (CUNHA, 2011, p. 30). Posterior à Manchete, a mesma editora digitalizou o conteúdo das revistas Ele Ela e Fatos \& Fotos. Das semanais de informação geral, a revista Isto É estreou no ciberespaço em 1996, ficando primeiramente hospedada no portal do Universo Online (UOL); já a atuação da concorrente Veja na internet começou quatro horas após a Isto É. No mês de novembro do mesmo ano, diversos títulos da Editora Abril possuíam páginas online, entre eles: Exame, Vip, Placar, Exame Informática, Superinteressante e Macmania.

Em maio de 1998, a editora IDG lançou o site das revistas Computerworld, Networkworld, Reseller World, PC World, Publish e WebWorld, esta última com circulação exclusiva na internet. Em agosto, ocorreu o lançamento da revista independente CameraSurf, voltada aos adeptos da prática do surf, com boletins diários das ondas, além 
de previsões meteorológicas. Em junho foi a vez da revista Bravo! ganhar sua versão on-line no portal UOL. Em setembro do mesmo ano, a editora Motorpress passa a disponibilizar a versão on-line das revistas Racing (automobilismo), Carro (automóveis, testes, comparativos, tabela de novos e usados) e Motociclismo Magazine (estreando com sorteio de moto) (CUNHA, 2011, p. 31).

A emergência destes e de outros dos sites não determinou o desuso dos CD-ROM. Nos anos 2000, tais suportes permaneciam lançando suplementos e agregando novidades em termos de linguagem, como a inserção de áudio e vídeo em seus conteúdos. Já as revistas inglesas Exact Editions e Quickly veicularam as primeiras edições fac-símile em seus sites no ao de 2006 (QUINN, 2007). Na primeira década do século 21, os celulares (telefones móveis) começam a ser usados como artefato de consumo de informação, inclusive de produtos jornalísticos. Quinn (2007), em sua cronologia, aponta que, no Reino Unido, as revistas Time Out, OK!, Glamour, GQ permitiam a realização do download em celulares a partir de 2006, na plataforma conhecida como Mobizine.

A cada ano, os avanços tecnológicos se estabeleciam com menor intervalo temporal, o que intensificava a inserção dessas novidades no jornalismo de revista. Um desses exemplos é o ano de 2007, que, na cronologia de Quinn (2007), marcou o lançamento de sites de revistas para adolescentes (Jellyfish), a entrada de publicidade nas páginas, a incorporação de TV Digital a revistas (Nuts), o lançamento de sites de revistas gratuitas (ShortList), e o lançamento de DVDs por algumas revistas (Expansive Media). Porém, as revistas em formatos digitais só começaram a se estabelecer como medium em 2008, a partir já do número alto de títulos das principais editoras, como a Ceros (200), a Zinio (850) e a Exact Edition (70) (QUINN, 2007).

Na sequência, o ano de 2009 marcou a inserção dos aplicativos (apps) da Apple no mercado da comunicação, a partir do aparelho móvel iPhone. A NME criou, em seu app, uma revista online, mesclando também televisão e áudio. No Brasil, as principais revistas semanais de informação geral - Veja, Época e Isto É - possuem versões voltadas para a plataforma. Um ano depois, em 2010, foi a vez do lançamento tablet iPad, também da Apple, e a adesão de publicações como Wired, Financial Times, The Spectador, dentre outras, tornando-se o mais recente espaço para recriação da linguagem jornalística das revistas. 


\section{A influência da materialidade do dispositivo na lógica do produto}

Nesse processo de digitalização - do eletrônico para o binário -, que já dura quase 30 anos, pelo menos por quatro "artefatos" (objeto desenvolvido pelo homem, para ser genérico) passaram ou se mantiveram as revistas jornalísticas, objeto do presente artigo. Entre eles, estão os CDROM, os desktops ou notebooks, telefonia móvel (celulares) e tablets, sendo o iPad, da Apple, o mais sofisticado. São essas matérias estruturantes, pelas quais emergem o conteúdo jornalístico do referido produto, que influenciam a lógica de distribuição e consumo da informação, como defendem os teóricos das materialidades da comunicação.

A delimitação teórica tem sido orientada para os estudos da área das Ciências da Comunicação por pesquisadores como Erick Felinto, André Lemos, Michael Hanke, Vinícius Pereira, Simone Sá, entre outros, com base nos esforços, com vistas à maturidade teórica, empregados principalmente pelo contemporâneo Hans Ulrich Gumbrecht. Esse alemão defende que a materialidade do objeto que armazena a informação é determinante na compreensão da mensagem. Por essa premissa, o estudioso critica o paradigma hermenêutico pela independência - e autonomia - que se dá à interpretação, por ela estar apenas "fundada na figura central do sujeito" (GUMBRECHT, 1998, p. 138).

Para ele, a necessidade de (sempre) interpretar subestima a capacidade da mensagem de se revelar em si mesma, como critica: "Desse modo, não apenas o corpo é um instrumento secundário de articulação, também a expressão se revela insuficiente. Em virtude dessa premissa, no interior do paradigma hermenêutico se impõe a necessidade da interpretação". Como resultado desse sistema, o autor acredita que, de modo negativo, "[...] estabelece-se uma identidade entre o que o sujeito desejava interpretar e o entendimento do intérprete" (GUMBRECHT, 1998, p. 140).

A materialidade seria, portanto, o primeiro e principal estágio para o alcance da interpretação: "A crítica à interpretação não quer excluir o nível do significado, mas 'materializar' o discurso das ciências da cultura, e questionar a tradição, segundo a qual a interpretação seja a prática exclusiva das ciências humanas" (HANKE, 2005, p. 3). Felinto (2001) ressalva que a abordagem do alemão não é inédita, apenas visa à renovação da questão 5 .

5 Felinto (2001) lembra a proximidade de Walter Benjamin e Marshall McLuhan com esta questão. 
A formação da interpretação, por meio da materialidade, é um dos aspectos. Outra consequência é a determinação da "estruturação da mensagem comunicacional" (FELINTO, 2001), isto é, a forma que ela adquire a depender da capacidade tecnológica de cada dispositivo. Entre as possíveis aplicabilidades da teoria nos estudos da Comunicação, uma das preocupações de Felinto (2001) é a reflexão sobre as novas tecnologias da comunicação e informação, desdobrando-a em aspectos como a interação entre "corpo e máquina, sistemas de pensamento humano e sistemas binários, entre o real e o virtual", por exemplo.

Diante do apresentado, a materialidade dos objetos pode ser estudada tendo em vista a "situação material" do usuário a partir de situações como: a) "ritmos corporais"; b) "configuração do espaço onde se situa o aparato tecnológico"; e c) "estruturação de seus mecanismos de interface (teclado, mouse)" (FELINTO; PEREIRA, 2005, p. 81).

[...] uma análise da materialidade revela diversos agentes (dispositivos, produtores de textos, criadores de software, de imagens e de sons, usuários e suas práticas e hábitos corporais, lugares constituídos, distribuidores, escritores etc.) que atuam diferentemente a depender do conteúdo, do dispositivo e das práticas corporais (LEMOS, 2012, p. 122).

Latour (2005 apud Lemos, 2012) defende a implicação da interação entre os atores humanos e não humanos como prática "fundamental" para constituir a mobilidade comunicativa do consumo informativo, enfatizando a presença dessa relação em toda a história da leitura, a partir da adaptação do homem aos diferentes suportes, entre eles, "tabuletas, pergaminhos, papiros, códex, computador, internet, celulares, e-readers, tablets..." (LEMOS, 2005, p. 122).

Em relação às revistas, é interessante levar em conta as características que fazem parte da natureza do próprio produto para compreender se há influências relevantes nessas alterações de materialidade. Ressalte-se que, como os livros ou qualquer outro produto informativo, os suportes são múltiplos, podendo o mesmo conteúdo estar em um e-reader ou no papel. Do mesmo modo, há produtos desenvolvidos exclusivamente para um determinado lócus, o que deve servir para explorar as potencialidades dos códigos linguísticos do ambiente específico (por exemplo, a hipertextualidade, a interatividade e a multimidialidade, no caso dos digitais).

Lidar com materialidades diversas é hábito não superado desde quando as revistas anexavam à capa o CD-ROM como covermound. Porém, esses kits funcionavam como suplemento, oferecendo conteúdo diverso 
ao do impresso. Nesse sentido, em relação ao suporte, o usuário tinha que manusear a edição de papel, passível de maior portabilidade, justamente por não depender de outro suporte para funcionar - no caso do CD-ROM, é necessário computador, por exemplo.

O impresso até hoje propicia que os leitores tenham maior liberdade na posição de leitura (deitado, sentado ou em pé) e, como decorrência, no local onde lerá (cama, sofá ou fila do banco, por exemplo). Tal cultura não se dá apenas pelo tipo do suporte - impresso -, mas também pela habilidade no movimento de folhear, facilitada pelo modo em que as páginas são coladas no formato-revista (diferente no jornal, com páginas soltas e formato maior, o que dificulta o manuseio em pé, por exemplo). Nos dois casos, impressos e CD-ROM, os produtos são "fechados" (LEMOS, 2005), com conteúdo não manipulável pelo público leitor. André Lemos realiza a comparação dos usos com base nos jornais impressos, mas as afirmações servem de analogia ao que acontece nas revistas:

O jornal impresso tem o papel como suporte, onde os caracteres estão previamente fixados. Ele é um produto acabado, como uma temporalidade própria (quotidiano em sua maioria) que indica uma determinada postura corporal (sentado, folheando as páginas) e momento especial de leitura, mais focado, já que o produto é oferecido de forma finalizada ao leitor. Ele é barato, portátil e descartável (LEMOS, 2012, p. 120).

Aos poucos, com o desuso do CD-ROM e a passagem das revistas para as páginas na web (transição descrita no primeiro tópico), a lógica novamente se altera. Parte dos leitores e novos consumidores passaram a consumir informação também na tela de computador/notebook; e, mesmo que eles leiam no impresso conteúdo idêntico, a experiência não é fidedigna. Na tela, as revistas se apresentam de diferentes formas: páginas de sites, no estilo tradicional; PDF (conhecidos como pdf-mags), além de variações, como sites que armazenam web-reportagem em intervalos periódicos e se denominam magazines.

Apesar da diversidade, o meio de acesso à informação é a tela, suporte que traz consequências como: toque indireto no conteúdo, que ocorre tendo o teclado ou o mouse como mediadores; posição sentada como a mais confortável - é possível consumir o conteúdo deitado, mas por um período curto, para relaxamento; e em pé, diante de alguma necessidade urgente. Lemos (2012) comenta a situação da postura quando abordado o comportamento em relção ao jornal na web: 
A postura corporal é bem diferente daquela do leitor do jornal impresso. O corpo curva-se sobre uma máquina, através de uma interação indireta (através de mouse e pads, diferente dos tablets e e-readers cuja ação é mais direta, semelhante à manipulação do papel). Além disso, convoca uma posição parecida com aquela de quem trabalha com computadores (LEMOS, 2012, p. 120-121).

A portabilidade de uma revista na web é relativa. Hoje, o leitor pode transportar notebooks, mas dificilmente realiza a ação com um computador desktop como ocorreu entre a década de 1990 e o início dos anos 2000 (a presença dos desktops parece mais costumeira em ambientes de trabalho do que em casa, atualmente). Em relação ao conteúdo, ele pode ser aberto e/ou fechado, a depender da proposta da revista - nem todos oferecem o conteúdo do impresso gratuitamente; o conteúdo é geralmente ofertado apenas para assinantes.

Por outro lado, há a possibilidade de o leitor interagir com o conteúdo da revista, principalmente se ela tiver caráter multilinear, o que já diferencia a leitura de um impresso ou CD-ROM com a página na internet. A interação está presente, com mais intensidade, também nos canais de participação disponibilizados para o público, seja em comentários anexados à própria matéria/reportagem, envio de e-mail para o repórter que escreveu o conteúdo ou para a editoria, contato através de redes sociais.

Ao perceber as revistas já consolidadas nos dispositivos móveis, smartphones ou tablets, a principal diferença apontada é o retorno das características tradicionais do suporte impresso, adaptado na tela tátil (touchscreen), que retira a mediação direta do teclado ou mouse no acesso à informação. Ou seja, o contato do consumidor com a revista é simulado pela tecnologia tátil, gerando maior proximidade no ato de leitura. Outro apontamento comum entre os dois suportes - smartphones e tablets - quando comparado com a web diz respeito à limitação da dispersão da leitura, já que ela é possibilitada através de aplicativos nestes dispositivos. Em outros termos, o consumo nos apps ocorre de modo distinto das telas de computador: o foco é no aplicativo, não na "imensidão" da web.

Ainda entre as semelhanças, a portabilidade é comum e ampla a ambos os suportes, o que possibilita, como nas revistas impressas, guardá-los em bolsas, ler sentado em banco do carro ou do metrô, na fila de banco ou deitado na cama, apenas entre alguns exemplos. $O$ tamanho e o peso geralmente não são inconvenientes. Porém, como as materialidades são distintas, a estruturação ou interpretação do conteúdo apresentado não são iguais, principalmente por conta da dimensão da tela. 
Nos smartphones, cuja tela tem, em média, 4" (quatro polegadas) ${ }^{6}$, as notícias dos aplicativos, tendo como exemplo a revista Veja, são relacionadas em forma de lista, uma abaixo da outra, como um plantão de notícias. Ao clicá-las, o leitor é remetido para uma página que geralmente está composta com uma foto, no topo, e, abaixo, o texto, obedecendo à diagramação das revistas impressas. No caso da Isto É, para diferenciar, há uma foto ao lado de algumas notícias que estão listadas. Quando se clica sobre ela, aparece uma página com a mesma estruturação noticiosa, foto e texto. $O$ rolamento da página ocorre de modo verticalizado. Como já dito, para acesso à revista, é necessário baixar geralmente um aplicativo, que nos smartphones é gratuito.

Nos tablets, com telas que variam entre 7 e 9" (sete e nove polegadas) (CUNHA, 2012), mais que o dobro dos smartphones, a estruturação de conteúdo tem predisposição para criação de novas experiências de leitura (consumo), com narrativas dinâmicas, multimidiáticas, capazes de surpreender o usuário pela estética comunicativa. A facilidade de interação com o conteúdo pela tela tátil, permitindo rotacioná-lo, por exemplo, contribui para o contato mais próximo do usuário com a notícia e atende a opção de posição de leitura do usuário.

[...] o conteúdo pode ser outro, mais aberto, com links, interativo, multimidiático, adaptado à tela "touch-screen" e aos movimentos de rotação do equipamento, como os primeiros livros eletrônicos em CDROM! Por exemplo, ao usar o acelerômetro (rodá-lo e colocá-lo na horizontal ou vertical) uma imagem pode se transformar em um vídeo, por exemplo. A tela tátil permite uma interação mais complexa e intuitiva do que aquela com o teclado para a web, ou as teclas para passar as páginas de um e-reader. A ação corporal é diferente daquela do impresso ou da web, e bem mais próxima dos e-readers, embora a interatividade crie novas exigências de apoio do dispositivo, ou de movimentos característicos (LEMOS, 2012, p. 121-122).

Os tablets, portanto, dão luz à nova forma de concepção e consumo do conteúdo, nesse caso, das revistas jornalísticas, de modo a unir potencialidades da mídia digital e hábitos da cultura impressa. Nesse sentido, vale ressaltar a formatação "fechada" do produto - ou seja, como o smartphone, o consumo é feito via aplicativo, sem a necessidade de digitar o endereço no navegador. Porém, o aspecto que os distingue é a

6 Disponível em: <http://migre.me/a4tVl>. Acesso em: 28 jul. 2012. 
formatação do produto - no tablet, a revista possui capa, sumário, publicidades, simulação de folhas paginadas e do ato de folhear -, além do design, em tudo aproximado ao impresso. Na maioria dos casos, os aplicativos são pagos.

\section{Considerações finais}

As descrições acima ajudam a refletir acerca da materialidade dos dispositivos e as suas consequências para a estruturação e distribuição do conteúdo nas revistas. Abordagem materialista contribui para melhor entender "a vida dos objetos", como indica o título de um dos artigos de Erick Felinto e Vinicius Andrade (2005) sobre o tema. Os autores enfatizam que a teoria ainda não está delimitada conceitual e metodologicamente, constituindo etapa de work in progress. Entre as certezas, sabem que o universo defendido tem o corpo como objeto central, "com todas as inscrições que sofre em suas relações com o poder e os aparatos tecnológicos (FELINTO; PEREIRA, 2005, p. 84).

No artigo, em sua primeira etapa, foram descritas as principais passagens da recente história da digitalização das revistas jornalísticas, produto que tem consolidado a sua distribuição nas interfaces virtuais. Atualmente, é possível perceber que, cada vez mais, novas produções têm se autodenominado revista, renovando, inclusive, a sua natureza a partir do uso das tecnologias da informação e comunicação, e da disposição em atender as frentes de interatividade abertas pelas redes sociais. Nesse caso, é possível abranger as chamadas "revistas sociais", acessadas através de aplicativos voltados, principalmente, para os tablets.

Além do impresso, suporte tradicional do produto que se sustenta ainda na era tecnológica, na transição entre o eletrônico e a mídia binária, a revista passou pela fase dos CD-ROM, que abrigava o próprio produto ou suplementos da edição, caracterizando-se pela dependência de outro suporte - o computador - para funcionar, mas que foi o primeiro indicativo das possibilidades multimídias; também pelos websites, que depende da internet, possui navegação multilinear, formata um produto "aberto" (sites) e mantém um distanciamento maior entre produto e usuário.

Em paralelo aos sites, plataforma típica da internet e que permanece ativo, a tecnologia começa a ser transferida para os celulares, que são dispositivos com maior mobilidade que os anteriores, por meio dos smartphones. Neles, as revistas aparecem em forma de aplicativo, como produtos "fechados" (usuário explora apenas o conteúdo do aplicativo, 
sem inserção de links que remetem a sites, por exemplo), geralmente de consumo gratuito, e que resgatam a portabilidade permitida pelos impressos - é possível o deslocamento irrestrito, sem incômodo quanto ao peso ou tamanho do objeto. Além disso, suporte também proporciona conforto, uma vez que o usuário pode ler o conteúdo em posições diversas, não apenas sentado em frente ao computador - como nos CD-ROM e sites (via desktops).

Por fim, até o momento, a última etapa em que se alocam as revistas jornalísticas fica com os tablets, que também são dispositivos móveis, mas não possuem o serviço de telefone e são desenvolvidos com vistas à leitura (e-reader). Nesses aparatos, as revistas podem ser consideradas carros-chefe em meio a produtos jornalísticos como jornais, porque, pela característica da própria natureza (que sempre ousou na fotografia, por exemplo), pode criar novas experiências imagéticas na construção do conteúdo. As revistas, nos tablets, são produtos "fechados", consumidos por meio de aplicativos pagos. Há a comodidade no ato de leitura, tanto pela portabilidade (o objeto pode ser levado em bolsas e mochilas sem representar aumento significativo no peso), quanto pela liberdade na posição de leitura, mantendo o conformo em pé, deitado ou sentado.

Como pontuado no artigo, o propósito deste estudo foi repensar as revistas em formatos digitais a partir da observação de seus diferentes suportes. $\mathrm{O}$ artigo foca em aspectos como postura do leitor, portabilidade e potencialidades do meio, o que resulta na consideração de que as diferenças são frequentes quando as revistas mudam de suporte, como pôde ser destacado. Diante desse cenário introdutório no universo das revistas, é possível aprofundar a questão em dois desdobramentos: (1) análise da estrutura das notícias nos diferentes dispositivos digitais (websites, smartphones e tablets) e (2) reflexão do conceito das revistas (o que é revista?) a partir das transformações - e novas produtos - tecnológicas; esse aspecto é desenvolvido na dissertação de mestrado da autora, intitulada "Revistas em formatos digitais: modelos e novas práticas jornalísticas", defendida no mês de fevereiro de 2013 na Universidade Federal da Bahia.

\section{Referências}

CUNHA, R. E. S. Revistas no cenário da mobilidade: a interface das edições digitais para tablets. Bahia, 2011. 100 f. Dissertação (Mestrado em Cibercultura) - Programa de Pós-Graduação em Comunicação e Cultura Contemporâneas, Universidade Federal da Bahia, Salvador, 2011. 
FELINTO, E. Materialidades da comunicação: por um novo lugar da matéria na teoria da comunicação. Ciberlegenda, n. 5, 2001. Disponível em: <http://migre.me/ a63aL>. Acesso em: 21 jul. 2012.

FELINTO, E.; PEREIRA, V. A vida dos objetos: um diálogo com o pensamento da materialidade da comunicação. Contemporânea, v. 3, 2005.

GUMBRECHT, H. U. O campo não-hermenêutico ou a materialidade da comunicação. In: ROCHA, J. C. C. Corpo e forma: ensaios para uma crítica não-hermenêutica. Rio de Janeiro: EdUERJ, 1998. p. 137-151.

HANKE, M. M. Materialidade da Comunicação - Um Conceito para a Ciência da Comunicação. In: CONGRESSO BRASILEIRO DE CIÊNCIAS DA COMUNICAÇÃO INTERCOM, 2005, Rio de Janeiro. Anais eletrônicos... Rio de Janeiro: Universidade Estadual do Rio de Janeiro (UERJ). Disponível em: <http://migre.me/a634A>. Acesso em: 21 jul. 2012.

LATOUR, B. Reassembling the social. An Introduction to Actor-Network Theory. Oxford: Oxford University Press, 2005.

LEIVA, M. T. G. Las revistas culturales y su futuro digital. Madrid: Ed. Fundación Alternativas, 2007.

LEMOS, A. Dispositivos de leitura eletrônicos. Revista Comunicação, Mídia e Consumo, v. 9, n. 24, 2012.

SOUSA, J. P. Jornalismo on-line. Revista Fórum Media, n. 5, 2002. Disponível em: <http://www.ipv.pt/forumedia/5/13.htm>. Acesso em: 21 jul. 2012.

QUINN, T. Digital magazines: a history. 2007. Available at: <http://bit.ly/cJbkv>. Access on: 21 jul. 2012.

ZAMITH, F. Dos jornais-fax de Moçambique aos web-jornais. 1999. Disponível em: <http://migre.me/a62lO>. Acesso em: 21 jul. 2012.

Recebido: 29/01/2013

Received: 01/29/2013

Aprovado: 26/02/2013

Approved: 02/26/2013 